\title{
The intravenously administered palonosetron does not affect the spinal anesthesia
}

\author{
Myoung-Hun Kim, Seunghee Ki, Kwangrae Cho, Wonjin Lee, and Sang-Min Sin \\ Department of Anesthesiology and Pain Medicine, Busan Paik Hospital, College of Medicine, Inje University, Busan, Korea
}

The 5-hydroxytryptamine Type 3 (5-HT3) antagonists are a class of drugs frequently used to prevent and treat nausea and vomiting. It has been shown that a 5-HT3 receptor exists in the spinal nerves and affects pain control in animals [1]. In one study, ondansetron administered to prevent nausea and vomiting interrupted sensory deprivation in spinal anesthesia performed with lidocain [2]. Another study showed that other 5-HT3 antagonists such as granisetron enhanced recovery of the sensory nerves during spinal anesthesia [3]. Palonosetron, a second-generation 5-HT3 receptor antagonist approved in 2003, is known to have the strongest affinity to the 5-HT3 receptor, with a receptor binding affinity about 30 times stronger than that of ondansetron and granisetron. In addition, its elimination half-life is about 40 hours, far longer than that of other 5-HT3 antagonists. Therefore, a small dose, generally $0.075 \mathrm{mg}$, is recommended to prevent nausea and vomiting after general operations [4]. However, as the effect of palonosetron on spinal anesthesia has not been studied, it is unclear whether preoperative administration of palonosetron interrupts the anesthetic effect. In this study, we investigated the effect of palonosetron on spinal anesthesia by examining the level of sensory block, the timing of sensory recovery, and the timing of motor recovery in spinal anesthesia performed with bupivacaine $8 \mathrm{mg}$ when palonosetron $0.075 \mathrm{mg}$ or normal saline solution $1.5 \mathrm{ml}$ was intravenously injected preoperatively.

This study was conducted with the approval of the Institutional Review Board at our hospital. The subjects were 80 American Society of Anesthesiologists (ASA) class I-II patients who were scheduled to undergo transurethral surgery under spinal anesthesia. The objective and methods of the study were explained to them before the operation, and informed consent was obtained from each patient. The subjects were randomly assigned either to a group in which normal saline solution 1.5 $\mathrm{ml}$ was injected 15 minutes before the operation (Group C) or to a group in which palonosetron $0.075 \mathrm{mg}(1.5 \mathrm{ml})$ was intravenously injected 15 minutes before the operation (Group P). Patients who had undergone lumbar surgery or those who had been administered drugs that could affect spinal anesthesia, such as an analgesic, a calcium channel blocking agent, or an alpha 2 agonist, were excluded from the study.

An anesthetist performed anesthesia without knowledge of the intravenously injected drug, and the same anesthetist observed the patients in the operating room and the recovery room. Vital signs such as electrocardiography, blood pressure, and oxygen saturation were monitored in the operating room. Before the induction of anesthesia, normal saline solution 300 $\mathrm{ml}$ was intravenously injected in all patients. Anesthesia was performed by having the patient lie in the lateral recumbent position and inserting a $25 \mathrm{G}$ Whitacre needle (Becton-Dickinson, Franklin Lakes, NJ, USA) through the midline of the L4-5 intervertebral space. After checking the outflow of the cerebrospinal fluid, $0.5 \%$ hyperbaric bupivacaine $8 \mathrm{mg}$ was injected for 10 seconds. After the injection, the patient adopted the supine position. After the sensory block was checked, the patient adopted the lithotomy position.

With respect to the sensory block, the level at which the pinprick sensation disappeared was recorded every 10 minutes, and the highest sensory block level was also recorded. The time to

Corresponding author: Myoung-Hun Kim, M.D., Department of Anesthesiology and Pain Medicine, Busan Paik Hospital, College of Medicine, Inje University, Geageum 2-dong, Busanjin-gu, Busan 614-735, Korea. Tel: 82-51-890-6520, Fax: 82-51-898-4216, E-mail: pain_kill@naver.com () This is an open-access article distributed under the terms of the Creative Commons Attribution Non-Commercial License (http:// creativecommons.org/licenses/by-nc/3.0/), which permits unrestricted non-commercial use, distribution, and reproduction in any medium, provided the original work is properly cited. 
Table 1. Sensory and Motor Recovery Time

\begin{tabular}{lccc}
\hline & $\begin{array}{c}\text { Group C } \\
(\mathrm{n}=40)\end{array}$ & $\begin{array}{c}\text { Group P } \\
(\mathrm{n}=40)\end{array}$ & P value \\
\hline Sensory recovery by two dermatome (min) & $82.3 \pm 17.9$ & $74.5 \pm 17.5$ & 0.054 \\
Sensory recovery to S1 (min) & $199.5 \pm 19.3$ & $205.8 \pm 30.7$ & 0.280 \\
Able to bend knee (min) & $105.8 \pm 31.1$ & $112.8 \pm 42.0$ & 0.400 \\
Able to dorsiflex the foot (min) & $136.5 \pm 30.3$ & $114.0 \pm 44.1$ & 0.379 \\
\hline
\end{tabular}

The values are the mean and standard deviation. Group C: Normal saline group. Group P: Palonosetron group.

regression of sensory block by two dermatomes and the time to recovery of sensory function at the $\mathrm{S} 1$ level were also recorded. The motor block was measured every 10 minutes using the modified Bromage scale $(0=$ No block, $1=$ Able to bend knee, 2 $=$ Able to dorsiflex the foot, and $3=$ Complete motor block).

There were no significant differences between the two groups in age, height, weight, sex, and ASA class. The highest sensory block level in the thoracic dermatome was $9.0 \pm 1.2$ in Group $\mathrm{P}$ and $9.1 \pm 1.1$ in Group C, indicating no significant difference $(\mathrm{P}=0.847)$. The time to regression of sensory block by two dermatomes was $74.5 \pm 17.5$ minutes in Group P and $82.3 \pm 17.9$ minutes in Group C, indicating no significant difference ( $\mathrm{P}=$ $0.054)$. The time to recovery of sensory function at the S1 level was $205.8 \pm 30.7$ minutes in Group P and $199.5 \pm 19.3$ minutes in Group C, indicating no significant difference. No significant difference was found between the two groups in the time to recovery from motor nerve block (Table 1).

These results showed that the dose of palonosetron generally administered to prevent postoperative nausea and vomiting had no particular effect on sensory and motor block or on recovery in spinal anesthesia using bupivacaine. This finding may be attributable to $0.075 \mathrm{mg}$ of palonosetron having a sufficient effect on the chemoreceptor trigger zone but being insufficient to affect the bupivacaine in the intervertebral space. However, the comparison of the time to regression of sensory block by two dermatomes showed that the recovery tended to be more rapid in the palonosetron group, although the difference was not significant. It can be assumed, therefore, that the effect of palonosetron may depend on the type and dose of the spinal anesthetic. In addition, considering that the appropriate dose of palonosetron for patients undergoing carcinostatic therapy is $0.25 \mathrm{mg}$, more studies may be necessary to examine the effect of highdose palonosetron administration on sensory block after spinal anesthesia. In conclusion, intravenous injection of palonosetron $0.075 \mathrm{mg}$ for the reduction of postoperative nausea and vomiting had no effect on the sensory block level and recovery from sensory and motor block in spinal anesthesia performed using bupivacaine $8 \mathrm{mg}$.

\section{References}

1. Fassoulaki A, Melemeni A, Zotou M, Sarantopoulos C. Systemic ondansetron antagonizes the sensory block produced by intrathecal lidocaine. Anesth Analg 2005; 100: 1817-21.

2. Mowafi HA, Arab SA, Ismail SA, Al-Ghamdi A. The effects of intravenous granisetron on the sensory and motor blockade produced by intrathecal bupivacaine. Anesth Analg 2008; 106: 1322-5.

3. Samra T, Bala I, Chopra K, Podder S. Effect of intravenous ondansetron on sensory and motor block after spinal anesthesia with hyperbaric bupivacaine. Anaesth Intensive Care 2011; 39: 65-8.

4. Rojas C, Thomas AG, Alt J, Stathis M, Zhang J, Rubenstein EB, et al. Polonosetron triggers 5-HT3 receptor internalization and causes prolonged inhibition of receptor function. Eur J Pharmacol 2010; 626: 193-9. 